\title{
EGFR NM_005228.3:C.2156G>C
}

National Cancer Institute

\section{Source}

National Cancer Institute. EGFR NM 005228.3:C.2156G>C. NCI Thesaurus. Code C98521.

A nucleotide substitution at position 2156 of the coding sequence of the EGFR gene where guanine has been mutated to cytosine. 